\title{
Effects of Simplicillium lanosoniveum on Phakopsora pachyrhizi, the Soybean Rust Pathogen, and Its Use as a Biological Control Agent
}

\author{
N. A. Ward, C. L. Robertson, A. K. Chanda, and R. W. Schneider
}

Department of Plant Pathology and Crop Physiology, Louisiana State University Agricultural Center, Baton Rouge 70803. Current address of N. Ward: Department of Plant Pathology, University of Kentucky, Lexington 40546. Accepted for publication 13 April 2012.

\begin{abstract}
Ward, N. A., Robertson, C. L., Chanda, A. K., and Schneider, R. W. 2012. Effects of Simplicillium lanosoniveum on Phakopsora pachyrhizi, the soybean rust pathogen, and its use as a biological control agent. Phytopathology 102:749-760.

The fungus Simplicillium lanosoniveum was isolated from soybean leaves infected with Phakopsora pachyrhizi, the soybean rust pathogen, in Louisiana and Florida. The fungus did not grow or become established on leaf surfaces until uredinia erupted, but when soybean rust signs and symptoms were evident, S. lanosoniveum colonized leaves within 3 days and sporulated within 4 days. Development of new uredinia was suppressed by about fourfold when $S$. lanosoniveum colonized uredinia. In the presence of $S$. lanosoniveum, uredinia became increasingly redbrown, and urediniospores turned brown and germinated at very low
\end{abstract}

ABSTRACT rates. Assays using quantitative real time polymerase chain reaction revealed that the fungus colonized leaf surfaces when plants were infected with $P$. pachyrhizi, either in a latent stage of infection or when symptoms were present. However, when plants were inoculated before infection, there was no increase of DNA of $S$. lanosoniveum, suggesting that the pathogen must be present in order for the antagonist to become established on soybean leaf surfaces. We documented significantly lower amounts of DNA of $P$. pachyrhizi and lower disease severity when soybean leaves were colonized with $S$. lanosoniveum. These studies documented the mycophilic and disease-suppressive nature of $S$. lanosoniveum.

Additional keywords: Cordycipitaceae, Glycine max.
Soybean rust, caused by Phakopsora pachyrhizi Sydow, was discovered in the United States in $2004(29,34)$. Since becoming established in the Gulf South, it was speculated that the disease would spread into the Midwest and cause devastating yield losses as seen in Africa, Asia, and South America (17,37). Recent reports documented yield losses of 35 to $40 \%$ in Louisiana and over $80 \%$ in Florida on highly susceptible soybean cultivars that were not protected with a fungicide (35).

Research efforts in disease management have focused on evaluating fungicides and optimizing rates and times of application $(17,30)$. In spite of these efforts, control of soybean rust is not always feasible because of specific application requirements. Preventative applications of protectant fungicides must be accurately timed because they may not be effective if disease is already present at very low levels (30). Furthermore, breeding efforts have yet to produce resistant cultivars (10).

Although there has been interest during the past 30 years in identifying microorganisms that are antagonistic to rust fungi, there are relatively few reports of such associations with $P$. pachyrhizi $(25,31,38)$. However, mycoparasitic interactions between Verticillium psalliotae (Lecanicillium psalliotae (Treschew) Zare \& W. Gams) and $P$. pachyrhizi were reported in which $V$. psalliotae formed appressoria-like structures at possible infection sites on urediniospores $(25,39)$. The primary mode of parasitism was reported to be degradation of urediniospores by $\beta$-glucanase, chitinase, and protease $(26,27)$. Other Lecanicillium spp. were reported as pathogens of aphids, scale insects, ticks, and whiteflies

Corresponding author: N. Ward; E-mail address: nicole.ward@uky.edu

* The $\boldsymbol{e}$-Xtra logo stands for "electronic extra" and indicates that the online version contains one supplemental figure. Figures 1 and 2 appear in color online.

http://dx.doi.org/10.1094/PHYTO-01-11-0031

(C) 2012 The American Phytopathological Society
$(2,9,19,22)$. A sister taxon, Simplicillium, was associated with ticks, nematodes, and scale insects as well as rusts, such as Hemileia vastatrix (coffee rust) and Uromyces pencanus $(3,13$, 23). Lecanicillium and Simplicillium (both formerly Verticillium spp.) are included in the family Cordycipitaceae, which also includes the anamorphic genera Beauveria and Isaria $(32,39)$. This family consists of entomopathogenic and mycoparasitic ascomycetes. Teleomorphs of Simplicillium are Torrubiella spp. (Cordycipitaceae), which are pathogens of spiders and scale insects $(3,7)$.

Although not reported as an entomopathogen or mycoparasite, S. lanosoniveum (J.F.H. Beyma) Zare \& Gams 2001 was recovered from the coffee rust pathogen, Hemileia vastatrix, and from scale insects on coffee (Centraalbureau voor Schimmelcultures; 39). Until recently, there were no documented cases in which $S$. lanosoniveum had been associated with $P$. pachyrhizi. However, $S$. lanosoniveum was recently reported to be the causal agent of brown spot on the aquatic ferns Salvinia auriculata and Salvinia molesta in Taiwan (8). In our studies, S. lanosoniveum did not cause lesions or necrosis on soybean in either coinoculated treatments or Simplicillium-only controls (unpublished data).

In 2007, we observed the mycophilic fungus S. lanosoniveum intertwined within, around, and suspended above uredinia (pustules) of $P$. phakopsora. Fungal growth was clearly associated with uredinia but absent on healthy leaf surfaces (36).

The objectives of this study were to examine $S$. lanosoniveum as a colonizer of uredinia of $P$. pachyrhizi and its effects on uredinial development, urediniospore production, and viability of urediniospores and to assess its potential as a biological control agent. This study examines the in situ interactions between $P$. pachyrhizi and S. lanosoniveum, and for this purpose we utilized field-grown naturally infected leaves rather than leaves from greenhouse-grown plants in order to more closely approximate 
host-pathogen-mycophilic fungus interactions as they would occur in the field. Furthermore, we evaluated the effects of $S$. lanosoniveum on soybean rust by inoculating plants with this fungus under field conditions. Colonization of soybean leaves by $S$. lanosoniveum and the rust pathogen were monitored using quantitative real-time PCR (qPCR) as well as visual disease ratings.

\section{MATERIALS AND METHODS}

Uredinial age study. Previous observations indicated that urediniospores turned brown with age. The following experiment was conducted in order to document the effects of uredinium age on urediniospore color. This experiment assessed age-related morphological traits of uredinia of soybean rust when $S$. lanosoniveum was present. Leaves were selected from susceptible, field-grown soybeans (Asgrow 6202; Monsanto; St. Louis, MO) that showed symptoms of soybean rust and had been assessed for disease severity as described below. Fifty leaflets were examined using a dissecting microscope at $25 \times$ magnification, and immature uredinia that had not yet erupted were marked. At least five uredinia were selected from each leaflet. These uredinia were numbered for reference. Leaflets were stored in plastic boxes lined with moist paper towels. Urediniospore production and color development were monitored daily during the 14-day duration of the experiment. Urediospores were rated as either brown or hyaline by examining under low magnification. For daily assessments, urediniospores were brushed away with an artist's paintbrush each day in order to examine newly produced urediniospores from the same uredinium. For cumulative assessments, urediniospores were allowed to accumulate in uredinia throughout the course of the experiment. Uredinia in both treatments were photographed daily. Experiments were repeated using the susceptible soybean cultivar Pioneer 95Y20 (Pioneer Hi-Bred; Johnston, IA).

Co-inoculations of disease-free soybean leaves. Detached soybean leaves were used to investigate the effects of $S$. lanosoniveum on uredinial development in P. pachyrhizi. A susceptible commonly grown soybean cultivar, Asgrow AG6202, was maintained at the Ben Hur Research Farm of the Louisiana State University Agricultural Center near Baton Rouge, Louisiana in 2007 according to standard practices (18). Insecticides were applied as needed, but no fungicides were used. Leaves without soybean rust symptoms were collected from mid-canopy from soybean plants at an early reproductive growth stage (R2) in a 10 $\mathrm{m}^{2}$ area of the field (11). Leaves were subsequently examined with a dissecting microscope to confirm the absence of uredinia.

Isolates of S. lanosoniveum (BH081707-1A [GenBank accession HQ270477] and D082307-2A [GenBank accession HQ270476]) collected from research stations in 2007 from Louisiana and Florida, respectively, were single-spored and maintained on potato dextrose agar (PDA) slants at $5^{\circ} \mathrm{C}$ (36). These two isolates had identical morphological traits and internal transcribed spacer (ITS) sequences (36). In this study, the two isolates were used to assess possible differences in reactions between these two disparate collection sites. Leaflets were coinoculated with either of the two isolates of S. lanosoniveum and urediniospores of $P$. pachyrhizi that had been collected from nearby fields. Additional details are provided below.

Inoculation of soybean leaves. Conidial inoculum was prepared by flooding 14-day-old PDA plates of $S$. lanosoniveum with sterile phosphate buffer $(0.5 \mathrm{mM}, \mathrm{pH} 7.1)$ plus $0.01 \%$ ( $\mathrm{vol} / \mathrm{vol}$ ) Tween 20 by gently rubbing colony surfaces with a glass rod. This buffer was used in all the experiments reported here. The resulting conidial suspensions were adjusted to $10^{6}$ conidia/ml with a hemacytometer. Urediniospores of $P$. pachyrhizi were harvested with a spore collector (G-R Manufacturing, Manhattan, KS) from field-grown soybean plants at the research farm less than 1 week before inoculations and stored in 20-ml vials at $-30^{\circ} \mathrm{C}$. Urediniospores were rehydrated in a moist chamber for $24 \mathrm{~h}$ before use (4). Urediniospore germination was determined by plating urediniospores onto $1.5 \%$ water agar and incubating for $6 \mathrm{~h}$ at $25^{\circ} \mathrm{C}$ in the dark. A urediniospore was considered germinated if the germ tube was at least as long as the urediniospore. Urediniospore lots with a germination rate of at least $90 \%$ were used for inoculations.

Three $4 \mathrm{~cm}^{2}$ subsampling areas were marked on the abaxial side of the apical leaflet of each of eight symptomless soybean leaves for each of the following treatments: (i) co-inoculation with $S$. lanosoniveum and $P$. pachyrhizi, (ii) sterile buffer only, (iii) $0.01 \%$ Tween 20 only, (iv) individual $S$. lanosoniveum isolate only, (v) urediniospores in $0.01 \%$ Tween 20 only, and (vi) a nontreated control. Sterile phosphate buffer was used to prepare all solutions and spore suspensions. Treatments ii and iii served as controls for the solutions without added inoculum, treatment iv determined whether or not $S$. lanosoniveum caused symptoms, treatment $\mathrm{v}$ served as a control for treatment $\mathrm{i}$, and treatment vi assessed background infection. Co-inoculations were accomplished by applying approximately 1,800 conidia of $S$. lanosoniveum to each marked area in $20 \mu \mathrm{l}$ with a micropipettor and spreading with a glass rod. After air drying for $1 \mathrm{~h}, 1,800$ urediniospores of $P$. pachyrhizi were similarly applied to the same subsampling area. Leaves were incubated in moist chambers made from clear polystyrene boxes $\left(30 \times 24 \times 8 \mathrm{~cm}^{3}\right)$ lined with moist paper towels. These moist chambers were incubated under cool white fluorescent lights (850 to 1,000 lux) with a $12 \mathrm{~h}$ photoperiod at $23^{\circ} \mathrm{C}$. Assuming that field-collected leaves could be latently infected, numbers of uredinia were determined on days 1 and 7 after inoculation because these uredinia would not have originated from the inoculation treatments. While this precaution would not account for all latent infections, uredinia did not develop in noninoculated controls during the course of this study. Therefore, we concluded that uredinial counts were representative of the experimental treatments.

Samples were processed for scanning electron microscopy (SEM) in order to visualize colonization of uredinia and urediniospores by $S$. lanosoniveum. Leaf tissue was fixed in formalin acetic acid overnight and then dehydrated in an ethanol series as follows (20 min in each solution): 50, 70, 95, and finally, $100 \%$. Samples were critical-point dried, coated with gold/ palladium (60:40) and viewed with a JEOL JSM-6610LV electron microscope (JEOL, Ltd., Tokyo, Japan) at the Louisiana State University Socolofsky Microscopy Center (24,28). Experiments were conducted three times.

To further investigate the effects of S. lanosoniveum on soybean rust, two isolates of $S$. lanosoniveum, D082307-2A and BH081707-1A, were applied individually to field-grown detached soybean leaves that showed symptoms of soybean rust. Symptoms included uredinia of various ages and stages of development as they occurred under field conditions. While no attempt was made to differentiate between young and old uredinia, this source of experimental error was minimized by using matched pairs of leaflets from the same trifoliolate leaf as described below. Soybean plants (Asgrow AG5903) were grown in fields as described above, and trifoliolate leaves with 5 to $10 \%$ of the leaf area covered with uredinia of $P$. pachyrhizi (Bayer Rating Scale; Bayer Crop Science; Kansas City, MO) were picked from midcanopy from plants with fully developed pods and early seed development (R5 growth stage) (11). After rinsing in distilled water $(\mathrm{pH} 7)$ for $10 \mathrm{~s}$, two opposite leaflets from each trifoliolate were detached and assigned to inoculated and noninoculated groups. Ten such leaflet pairs were assigned to each treatment and placed adaxial side down in moist chambers as described above.

One milliliter of a $S$. lanosoniveum conidial suspension, prepared as described above, was spread evenly across the abaxial surface with a glass rod. After inoculation, leaves were allowed to 
dry for $1 \mathrm{~h}$ before closing moist chambers. In contrast to coinoculations, this experiment did not use marked sample areas. Instead, entire leaf surfaces were inoculated with conidial suspensions of $S$. lanosoniveum. Because soybean leaves were already infected with $P$. pachyrhizi, additional inoculum of $P$. pachyrhizi was not applied. Additional treatments included sterile phosphate buffer only, $0.01 \%$ Tween 20 only, and a nontreated control as described above. This experiment was repeated with infected soybean leaves (Asgrow AG6202) from a different field at the research farm.

Uredinial development typically occurs after 7 to 10 days under laboratory conditions $\left(23^{\circ} \mathrm{C},>85 \%\right.$ humidity) (5). In these experiments, we rated leaves after 14 days for uredinial development, color of uredinia, and color of urediniospores in randomly selected fields of vision $\left(5 \mathrm{~cm}^{2}\right)$ using a dissecting microscope at $25 \times$ magnification. Red-brown uredinia, often associated with hypersensitive reactions, were characterized by dark halos or necrotic tissue surrounding the uredinium $(6,21)$. Tan uredinia had little or no dark surrounding tissue. These tan uredinia varied in urediniospore production; therefore, tan uredinia were subdivided into minimal, moderate, and maximum sporulation (Fig. 1). Maximum sporulation indicated that urediniospores were abundant enough that uredinia were not visible. Minimal sporulation de- scribed uredinia for which entire uredinia were visible because of the small number of urediniospores. Moderate sporulation included all those uredinia in which portions of the uredinia were visible. Three randomly selected subsamples with at least 25 nonoverlapping uredinia were selected for each leaflet for classification.

While uredinial color was apparent without the aid of a microscope, urediniospore color varied from hyaline to dark brown as a function of uredinial age and colonization by $S$. lanosoniveum. Therefore, a dissecting microscope $(25 \times$ magnification) was used to assess urediniospore color. Three fields of vision $\left(5 \mathrm{~cm}^{2}\right)$ were randomly selected from each leaflet for rating urediniospore color according to the following rating scale: $1=75$ to $100 \%$ hyaline urediniospores; $2=50$ to $75 \%$ hyaline urediniospores; $3=25$ to $50 \%$ hyaline urediniospores; $4=1$ to $25 \%$ hyaline urediniospores; and $5=$ no hyaline urediniospores. The experiment was conducted twice.

Urediniospore production and germination. The experiments described above were designed to determine whether $S$. lanosoniveum affected uredinium development. To determine whether inoculations with this fungus affected urediniospore production, leaves from each co-inoculation experiment were sampled 14 days after inoculation with urediniospores of $P$. pachyrhizi and

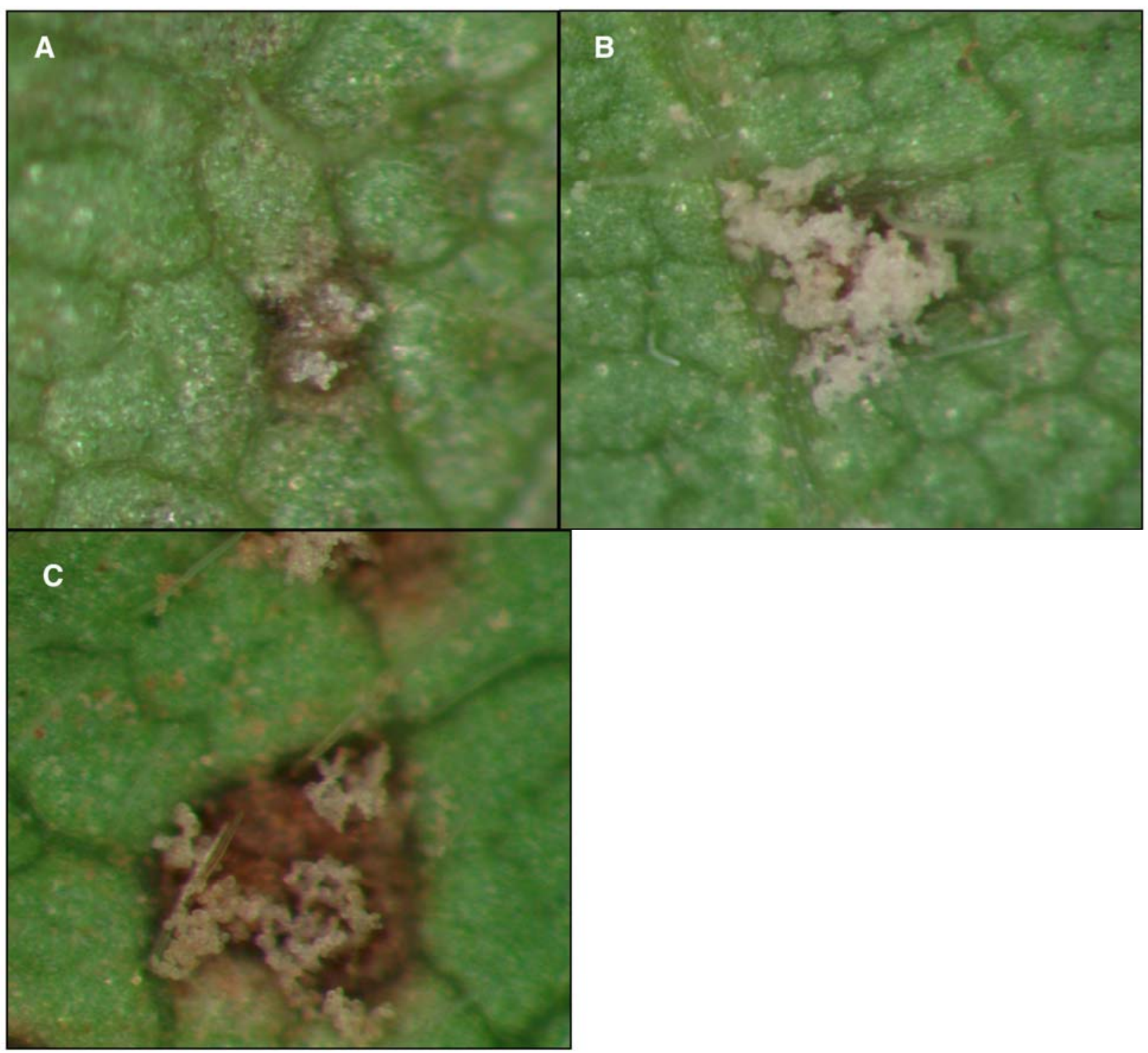

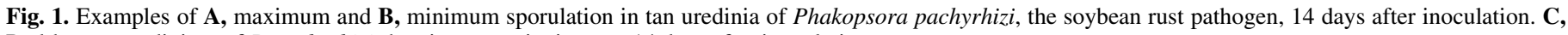
Red-brown uredinium of $P$. pachyrhizi showing necrotic tissue at 14 days after inoculation. 
conidia from $S$. lanosoniveum isolate D082307-2A to determine the number of urediniospores per uredinium. Three randomly selected leaf discs $\left(5 \mathrm{~cm}^{2}\right)$ were cut with a cork borer from each leaflet in the inoculated treatment and its paired nontreated control. Numbers of uredinia on each disc were determined with a dissecting microscope at $25 \times$ magnification. Discs were placed in $10 \mathrm{ml}$ of phosphate buffer with $0.01 \%$ Tween 20 and vortexed for $30 \mathrm{~s}$ to suspend urediniospores. Five samples were drawn from each suspension, urediniospores were counted with a hemacytometer (Hausser Scientific, Horsham, PA), and numbers of urediniospores per uredinium were calculated.

Germination tests were conducted to determine if there were differences in germination rates between hyaline and brown urediniospores. Uredinia that contained a majority of either hyaline or brown urediniospores were used in these experiments. Urediniospores were lifted with a needle from 10 uredinia of each urediniospore type described above and suspended in $1 \mathrm{ml}$ of $0.01 \%$ Tween 20 in phosphate buffer. Three such suspensions were made for each urediniospore type from inoculated and noninoculated treatments, and three subsamples (30 $\mu \mathrm{l} \mathrm{each)} \mathrm{were}$

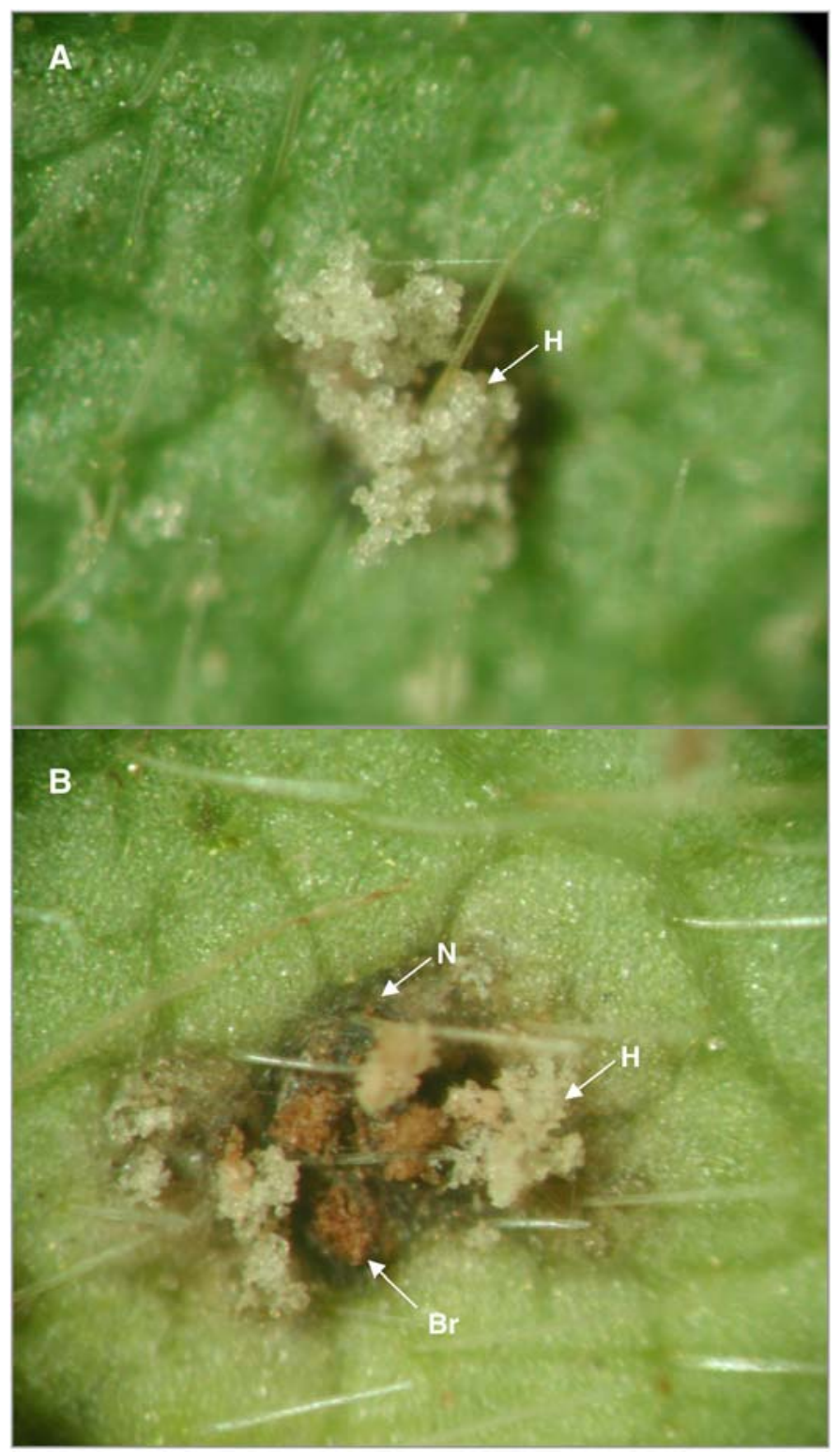

Fig. 2. Effects of soybean rust uredinial age on urediniospore color at $\mathbf{A}, 3$ and B, 10 days after the onset of sporulation by Phakopsora pachyrhizi, the soybean rust pathogen. Brown $(\mathrm{Br})$ and hyaline $(\mathrm{H})$ urediniospores, and necrotic leaf tissue $(\mathrm{N})$. drawn from each suspension for assessments of germination. Subsamples were spread individually across petri dishes containing $1.5 \%$ water agar. Fifty urediniospores were assessed for germination on each dish after incubation for $6 \mathrm{~h}$ at $25^{\circ} \mathrm{C}$ in the dark. A urediniospore was considered germinated if the germ tube was at least as long as the longest dimension of the urediniospore. The experiment was conducted twice.

Development of primers and probe. S. lanosoniveum. To develop highly specific primers and probe for detection and quantification of DNA of $S$. lanosoniveum, the ITS of the nuclear ribosomal RNA gene repeat was sequenced from five isolates of $S$. lanosoniveum that had been recovered from soybean leaves collected in Louisiana and Florida, as well as two additional isolates (CBS101895 and CBS70486) obtained from Centraalbureau voor Schimmelcultures (Utrecht, The Netherlands). Two other species of Simplicillium, S. obclavatum (CBS 51082) and $S$. lamellicola (CBS 13837), and other phylloplane inhabitants (Fusarium spp. and Cladosporium spp.) were evaluated to eliminate overlapping sequences and to prevent false positives. Genomic DNA was extracted from 14-day-old mycelia using Promega Wizard Genomic DNA Purification Kit (Promega Corp., Madison, WI). ITS primer pairs ITS1-F and ITS4 were used for DNA amplification (14). PCR product was purified with Millipore Montage PCR Centrifugal Filters (Millipore, Billerica, MA) and adjusted to $10 \mathrm{ng} / \mu \mathrm{l}$. PCR products from each isolate were sequenced at the DNA Sequencing Core/ICBR (University of Florida, Gainesville, FL) with the same primers used for amplification. All sequences were aligned with Clustal 2.0.11 (Conway Institute UCD, Dublin, Ireland). Primers and probe were designed to include all isolates of $S$. lanosoniveum and to exclude other species of Simplicillium and phylloplane inhabitants commonly isolated from soybean. Probe was labeled with $5^{\prime}$ 6-FAM (fluorescent reporter dye 6-carboxy-fluorescein) and with 3' TAMRA (quencher dye 6-carboxytetramethyl-rhodamine). Primers and probe were purchased from Integrated DNA Technologies (Coralville, IA).

Upon alignment of ITS sequences of $S$. lanosoniveum, Simplicillium spp., and other soybean phylloplane inhabitants, the following sequences for primers and probe were selected (Supplemental Figure 1). Forward primer SimpF-NW (5'-TTT ATCCAACTCCCAACCC-3') was specific to $S$. lanosoniveum. Reverse primer SimpR-NW (5'-CCGGGAGCCCCCTAG-3') was specific to the Louisiana and Florida isolates but different from the two CBS isolates of $S$. lanosoniveum by one or two bases. Probe SimpPR-NW (5'-FAM-CCTACCTTTATGTTGCTTCGGCG GTCT-TAMRA-3') was specific to $S$. lanosoniveum, and the last two bases of the $3^{\prime}$ end were highly specific to $S$. lanosoniveum (Fig. 2). Optimization of primers and probe for the qPCR instrument (ABI 7000, Applied Biosystems; Carlsbad, CA) yielded dilutions of $900 \mathrm{nM}$ of each forward and reverse primers and $200 \mathrm{nM}$ probe. Primers and probe developed for S. lanosoniveum were sensitive at less than $1 \mathrm{pg}$ of DNA per $10 \mathrm{ng}$ of total genomic DNA as calculated with the standard curve at a mean critical threshold value $(\mathrm{Ct})$ of 36.6. No cross reactivity was observed when tested against $S$. lamilicolla and $S$. obclavatum or against one isolate of Fusarium and three isolates of Cladosporium.

Integrity of the primers and probe was tested with dilutions of both pure $S$. lanosoniveum mycelial DNA and pure DNA spiked with soybean leaf DNA to identify possible inhibitors. A standard curve was generated by running six replications of 10 -fold dilutions of $10 \mathrm{ng}$ of genomic DNA from $S$. lanosoniveum plus 10 ng of DNA from soybean. Next, we evaluated various primers and probe concentration combinations to determine the lower threshold for detecting $S$. lanosoniveum. Specificity among $S$. lanosoniveum isolates was tested against dilutions of pure mycelial DNA of Fusarium and Cladosporium and soybean leaves infected with other pathogens such as Cercospora kikuchii and Septoria glycines. Assays were conducted twice. 
P. pachyrhizi. Primers and probe for detection and quantification of $P$. pachyrhizi were based on previous work (12). Primers Ppm1 (5'-GCAGAATTCAGTGAATCATCAAG-3') and Ppa2 (5'-GCAACACTCAAAATCCAACAAT-3') were reported to be specific to $P$. pachyrhizi. Specific probe (5'-FAM-CCA AAAGGTACACCTGTTTGAGTGTCA-TAMRA-3') was labeled at the $5^{\prime}$ end with the fluorescent reporter dye 6-carboxyfluorescein (FAM) and at the $3^{\prime}$ end with the quencher dye 6carboxytetramethyl-rhodamine (TAMRA). Primers and probe were purchased from Integrated DNA Technologies.

Field studies. Field experiments were conducted in three soybean fields in Louisiana and one field in Florida in 2009 and 2010. Suspensions of conidia and mycelial fragments of $S$. lanosoniveum were used to inoculate soybean leaves at various times as described below. Soybean rust epidemics were initiated from naturally occurring inoculum; plants were not inoculated with the soybean rust pathogen. Soybean crops were maintained according to recommended protocols with regard to insect and weed control and fertilization (18).

Preparation of inoculum. Conidial suspensions of $S$. lanosoniveum were prepared as described above for inoculation of soybean leaves. Two milliliters of this suspension was used to inoculate $100 \mathrm{ml}$ of potato dextrose agar that had been poured in the bottoms of 2-liter flasks. Flasks were shaken gently to spread inoculum across the solid agar surface. Cultures were incubated at $25^{\circ} \mathrm{C}$ in the dark for 7 days. At the time of inoculation in the field, flasks were filled with 2 liters of distilled water, shaken vigorously, and agar pieces were removed by straining the suspension through a wire mesh sieve with $500 \mu \mathrm{m}$ openings. Conidial suspensions were adjusted to $\mathrm{pH} 7.0$ with phosphate buffer (final concentration $0.5 \mathrm{mM}$ ) and amended with $100 \mu \mathrm{l}$ of Tween 20 per liter. The final inoculum concentration was approximately $10^{6}$ conidia $/ \mathrm{ml}$.

Mycelial inoculum was prepared by seeding $250 \mathrm{ml}$ of potato dextrose broth cultures with $2 \mathrm{ml}$ of the conidial suspension and shaken at $200 \mathrm{rpm}$ on an orbital shaker for 7 days at $25^{\circ} \mathrm{C}$ in the dark. Cultures were strained through a wire mesh sieve $(500 \mu \mathrm{m}$ openings), rinsed twice with deionized water, and blended in 500 $\mathrm{ml}$ of sterile phosphate buffer. Two hundred fifty milliliters of this suspension was added to each liter of conidial suspension to produce inoculum of $10^{4}$ colony forming units (CFU) per $\mathrm{ml}$ of mycelial fragments. Plants were inoculated with a hand-held garden sprayer immediately after inoculum was prepared.

To monitor colonization of S. lanosoniveum and $P$. pachyrhizi on soybean leaves, 10 trifoliolate leaves were sampled weekly from each plot beginning during the late vegetative stages or early reproductive stages of growth. Leaves were stored in freezer bags at $-20^{\circ} \mathrm{C}$ until they were processed for DNA extraction.

Field 1. The purpose of this experiment was to compare the two isolates of $S$. lanosoniveum and to determine whether they colonized uredinia of $P$. pachyrhizi under field conditions. Soybean cultivars Asgrow 6202, Deltagrow 4770 (Deltagrow Corp.), Deltagrow 4771, and Delta King GP-533 (Armor Seed Co.) were grown at the research farm near Baton Rouge, LA. Each replicate plot consisted of four rows spaced on $76 \mathrm{~cm}$ centers by $9 \mathrm{~m}$ long. The experiment was arranged in a randomized complete block design with four replications per cultivar. When disease severity reached at least $15 \%$ at 85 days after planting (DAP), the center two rows of each plot were inoculated with either BH081707-1A or D082307-2A with a hand-held sprayer at approximately 18 to $20 \mathrm{ml} / \mathrm{m}^{2}$. The nontreated control was sprayed with water only. Seven days after inoculation, 10 trifoliolate leaves were sampled from each plot for disease assessment and quantification of DNA of $P$. pachyrhizi and $S$. lanosoniveum by qPCR. Plots were inoculated again immediately after sampling (92 DAP) and sampled again 7 days later (99 DAP). Plants were sampled in October and November 2009 while they were at the R5 to R6 stage of reproductive growth (11).
Field 2. Soybean rust was detected within $44 \mathrm{~km}$ of the research farm on 5 June 2009, 46 days before soybeans were planted. To determine whether time of inoculation with $S$. lanosoniveum affected development of soybean rust, soybeans were inoculated with $S$. lanosoniveum isolate D082307-2A before and after disease symptoms occurred. Soybean cultivar Asgrow 6202 was planted in July 2009 at the research farm near Baton Rouge, LA. Individual replicate plots were 8 rows on $76 \mathrm{~cm}$ centers by $9 \mathrm{~m}$ long, and they were arranged in a randomized complete block design with four replications per treatment. The following four treatments were included: (i) inoculation with $S$. lanosoniveum at first flower (R1/R2, 38 DAP); (ii) inoculation with $S$. lanosoniveum at first occurrence of rust $(<2.5 \%$ severity) (R5, 68 DAP); (iii) application of pyraclostrobin fungicide (Headline, BASF Corp.), (876 $\mathrm{ml}$ of product in 187 liters of water per ha) at R1/R2; and (iv) nontreated control sprayed with water only. The center four rows of each plot were sprayed with inoculum of D082307-2A prepared as described above until leaves were wet (approximately 18 to $20 \mathrm{ml} / \mathrm{m}^{2}$ ). Fungicide application was applied with a tractor and plot sprayer (R\&D Sprayers, Opelousas, LA). Ten trifoliolate leaves were collected for qPCR analysis each week beginning during mid-vegetative stages (V4) and continuing through senescence (R7). One hour after each inoculation, three trifoliolate leaves were sampled from each plot to quantify initial inoculum.

Field 3. In July 2010, soybean cultivar Pioneer 95Y20 was planted at the University of Florida North Florida Research and Education Center in Quincy, Florida. There were four treatments in this experiment: (i) inoculation with $S$. lanosoniveum at first flower (R1); (ii) inoculation with $S$. lanosoniveum at beginning seed development (R3); (iii) application of pyraclostrobin fungicide as described above at V6/R1; and (iv) nontreated control sprayed with water only. Plots were four rows wide on 76 $\mathrm{cm}$ centers by $9 \mathrm{~m}$ long with six replications per treatment, and they were arranged in a randomized complete block design. The center two rows of each plot were inoculated with isolate D082307-2A as described above. Ten trifoliolate leaves were sampled weekly from each plot beginning during vegetative stages (V6) of growth and ending at the onset of senescence (R7) (89 DAP). Soybean rust was detected in kudzu (Pueraria lobata) approximately $180 \mathrm{~m}$ from the plots at 8 DAP. However, soybean rust was not detected in this field until 68 DAP when plants were in the R5 growth stage.

Assessments of soybean rust, $P$. pachyrhizi and $S$. lanosoniveum. Numbers of uredinia. Immediately after sampling, uredinia were counted on each apical leaflet from each of the 10 trifoliolates collected from each plot. Uredinia were counted within three fields of vision $\left(5 \mathrm{~cm}^{2}\right)$ per leaf with a dissecting microscope at $25 \times$ magnification, and uredinia per square centimeter were calculated for each leaflet.

DNA extractions. After determining numbers of uredinia, leaves from each plot were stored at $-20^{\circ} \mathrm{C}$ in plastic bags. For processing, leaves were ground in liquid nitrogen with a mortar and pestle. Subsamples of $50 \mathrm{mg}$ of ground leaf material were transferred to $1.5-\mathrm{ml}$ microcentrifuge tubes and ground again with plastic pestle grinders for $30 \mathrm{~s}$ in extraction buffer (Qiagen, DNeasy Plant Mini Kit, Hilden, Germany). Samples were incubated on a heating block at $55^{\circ} \mathrm{C}$ for 30 min during which time they were vortexed twice. Genomic DNA was extracted from the ground leaf samples using Qiagen's DNeasy Plant Mini Kit according to the manufacturer's protocol. Final DNA concentrations were determined and diluted to $10 \mathrm{ng} / \mu \mathrm{l}$ for use in $\mathrm{qPCR}$ assays.

qPCR assays. qPCR was used to quantify the amount of DNA of $S$. lanosoniveum and $P$. pachyrhizi from the extractions. Triplicate samples were tested in a total volume of $25 \mu \mathrm{l}$ per reaction. Each test for $S$. lanosoniveum included $10 \mathrm{ng}$ of template DNA, $12.5 \mu$ of TaqMan Universal PCR Master Mix 
(Applied Biosystems), $900 \mathrm{nM}$ each forward and reverse primer and $200 \mathrm{nM}$ probe. Reactions for P. pachyrhizi included $10 \mathrm{ng}$ of template DNA, $12.5 \mu$ of TaqMan Universal PCR Master Mix, $15 \mathrm{mM}$ primers Ppm1 and Ppa2, and $10 \mathrm{mM}$ FAM probe (12; Z. Y. Chen and S. Park, unpublished data). The qPCR instrument was programmed according to the following protocol: initial denaturation at $95^{\circ} \mathrm{C}$ for $10 \mathrm{~min}$ followed by 40 cycles of $95^{\circ} \mathrm{C}$ for $15 \mathrm{~s}$ and $60^{\circ} \mathrm{C}$ for $1 \mathrm{~min}$. The instrument software package automatically calculated $\mathrm{Ct}$ values for each reaction (16). For absolute quantification, $\mathrm{Ct}$ values were converted to picograms of DNA with standard curves.

Statistical analyses. For detached leaf experiments, treatments were arranged randomly in each moist chamber, and each moist chamber was considered to be a block in a randomized complete block design. All percentage data were transformed with the arcsine function and analyzed using the Kruskal-Wallis test. Parametric data, upon determining normality, were analyzed using analysis of variance (ANOVA) (1). For these parametric data, no more than two outliers were removed if they fell outside of the interquartile range, but these values are included in the relevant figures (33). Standard deviations (s.d.) are presented where appropriate. All experiments were repeated at least once. Statistical tests of interaction among repetitions were conducted where identical treatments were used. There were no significant interaction effects, and data for all repetitions were combined for analyses, although results for individual repetitions are presented where appropriate. For field experiments, data were first tested for normality and homogeneity of variances then subjected to analysis of variance in order to compare treatment means. To evaluate uredinial counts, numbers of uredinia per field of vision were averaged for each leaflet, and leaflet means were analyzed accordingly for each plot. DNA concentrations were analyzed after averaging triplicate subsamples for each field plot and these values were subjected to ANOVA. Statistical significance was established at $P<0.05$. JMP software version 9 (SAS Institute, Cary, NC) was used for all statistical analyses.

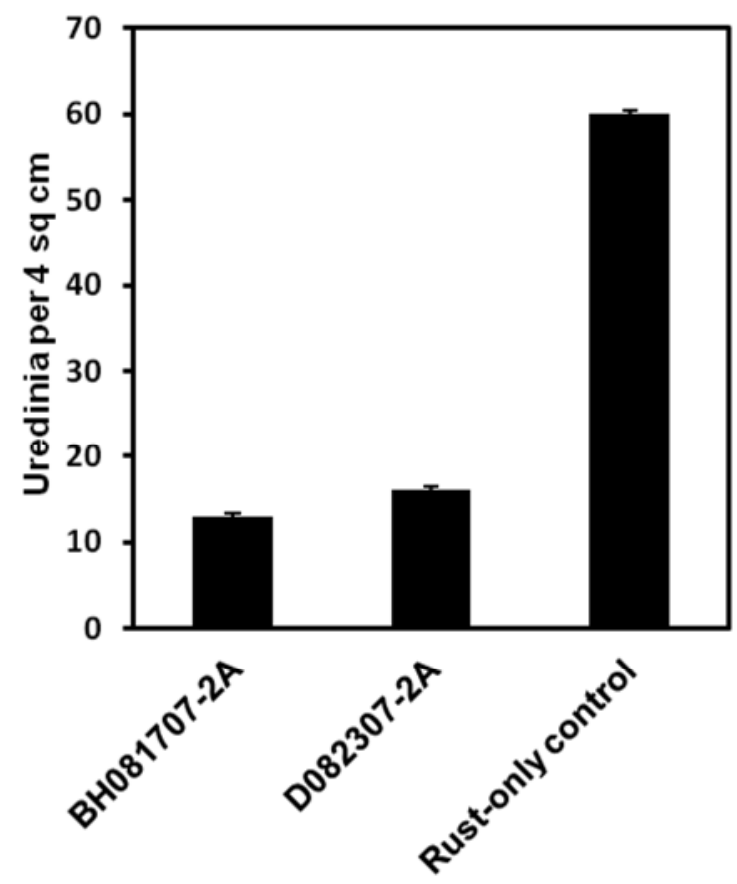

Fig. 3. Effect of co-inoculation of soybean leaves with conidia of two isolates of Simplicillium lanosoniveum (BH081707-2A and D082307-2A) and urediniospores of Phakopsora pachyrhizi on numbers of uredinia of P. pachyrhizi 14 days after co-inoculation. A sample area was a field of view through a dissecting microscope at $25 \times$ magnification $\left(4 \mathrm{~cm}^{2}\right)$. Bars represent standard errors of the mean.

\section{RESULTS}

Uredinial age study. Urediniospore color as a function of uredinial age was monitored and documented photographically. When urediniospores were brushed from uredinia daily, newly formed urediniospores were hyaline, regardless of the age of the uredinium. In uredinia in which urediniospores were allowed to accumulate, urediniospores became brown after 5 to 7 days (Fig. 2). Primary uredinia sporulated for 7 to 10 days, and secondary uredinia developed 5 to 7 days after development of primary uredinia. By day 14, sporulation of uredinia ceased. Urediniospores from older uredinia turned brown at the same age after eruption as urediniospores from younger uredinia. Likewise, urediniospores produced in secondary uredinia browned at the same age as those from primary uredinia. By days 10 to 14, leaf tissue around uredinia became necrotic, and as sporulation declined, uredinia appeared red-brown. Results were similar in both soybean cultivars.

Detached leaf experiments. Co-inoculations of disease-free soybean leaves. No rust symptoms were observed on days 1 and 7 following inoculations, indicating that subsequent symptom development was attributed to experimental inoculations rather than symptoms arising from latent infections that may have occurred in the field. Symptoms began to appear on day 10, and final uredinial counts were made on day 14 . The mean number of uredinia $/ 4 \mathrm{~cm}^{2}$ sample area was 112 (s.d. = 13.3) on leaves inoculated with $P$. pachyrhizi only. One outlier was removed from this data set which resulted in $61(\mathrm{~s} . \mathrm{d} .=3.5)$ uredinia $/ 4 \mathrm{~cm}^{2}$ sample area. The numbers of uredinia/4 $\mathrm{cm}^{2}$ sample area for leaves co-inoculated with $S$. lanosoniveum were about fourfold less compared with leaves inoculated with $P$. pachyrhizi only $(P=$ 0.001) (Fig. 3). By day 14, distinct mycelial masses were clearly visible within uredinia in the co-inoculated treatment under low magnification.

In the presence of soybean rust, $S$. lanosoniveum colonized uredinia and wrapped around urediniospores, and hyphae converged into putative penetration sites (Fig. 4). Simplicillium lanosoniveum did not colonize leaves that had not been inoculated with $P$. pachyrhizi, and we never observed the fungus on leaf surfaces in the absence of the rust pathogen. Soybean rust symptoms were not apparent in other treatments.

Inoculation of infected soybean leaves. Field-grown soybean leaves infected with $P$. pachyrhizi were inoculated with $S$. lanosoniveum, and uredinium counts were categorized by lesion color. By day 14, the treatment with isolate BH081707-1A had $78 \%$ (s.d. $=0.2$ ) red-brown lesions and $22 \%$ tan lesions, but upon removing two outlying data points, the treatment yielded $69 \%$ (s.d. $=0.3$ ) red-brown lesions and 33\% tan lesions. For both isolates there were significant increases in red-brown lesions $(P=$ $0.01)$ and significant reductions in tan lesions $(P=0.01)$ as compared to their noninoculated controls. In the presence of $S$. lanosoniveum, there were 2- to 2.5-fold more red-brown lesions as compared to noninoculated controls (Fig. 5).

In addition to uredinial color, urediniospore color also was documented in these experiments. After 14 days, isolates BH081707-1A and D082307-2A induced significantly more brown urediniospores in the inoculated leaflets compared with their paired controls ( $P=0.013$ and $P<0.001$, respectively) (Fig. $6)$. Repeated experiments yielded similar results.

Urediniospore production. To determine whether $S$. lanosoniveum affected numbers of urediniospores produced per uredinium, three subsamples were evaluated from each of three replications in field-collected infected leaves. Leaves inoculated with isolate D082307-2A of S. lanosoniveum yielded 407 (s.d. = 152.9) urediniospores per uredinium, while nontreated uredinia averaged $362($ s.d. $=240)(P=0.57)$. Likewise, leaves inoculated with isolate BH081707-1A yielded 470 (s.d. = 144) urediniospores per uredinium as compared to 500 (s.d. = 109) uredinio- 
spores per uredinium in the noninoculated control $(P=0.341)$. Thus, while urediniospore color was affected by $S$. lanosoniveum, the number of urediniospores per uredinium was not affected by either of the two isolates of $S$. lanosoniveum.

Hyaline urediniospores collected from inoculated uredinia had significantly higher germination rates than brown urediniospores $(P<0.001)$. Likewise, hyaline urediniospores recovered from noninoculated uredinia had a significantly higher germination rates than brown urediniospores recovered from the paired noninoculated uredinia $(P=0.01)$. There were no significant difference in germination rates for hyaline urediniospores from inoculated compared with noninoculated treatments. However, germination rates for brown urediniospores recovered from uredinia inoculated with $S$. lanosoniveum and those collected from noninoculated uredinia were significantly different $(P=$ 0.001) (Fig. 7).

Field studies. Field 1. In the late-planted field, rust severity was at least $25 \%$ at the time of inoculation with $S$. lanosoniveum. One hour after inoculation with isolate D082307-2A, there were $4.0 \mathrm{pg}$ (s.d. $=0.8$ ) of DNA of $S$. lanosoniveum per $10 \mathrm{ng}$ of soybean DNA. At 14 days after initial inoculation (7 days after second inoculation), DNA mass of both isolates of $S$. lanosoniveum increased significantly compared with the nontreated controls ( $P=0.02$ and 0.01 , respectively) (Fig. 8). Mean numbers of uredinia per square centimeter were 129.4 (s.d. $=22.1$ ), 164.2 (s.d. = 13.6), and 138.4 (s.d. = 22.1) for isolates D082307-2A, $\mathrm{BH} 081707$, and the nontreated control, respectively, on day 14 of

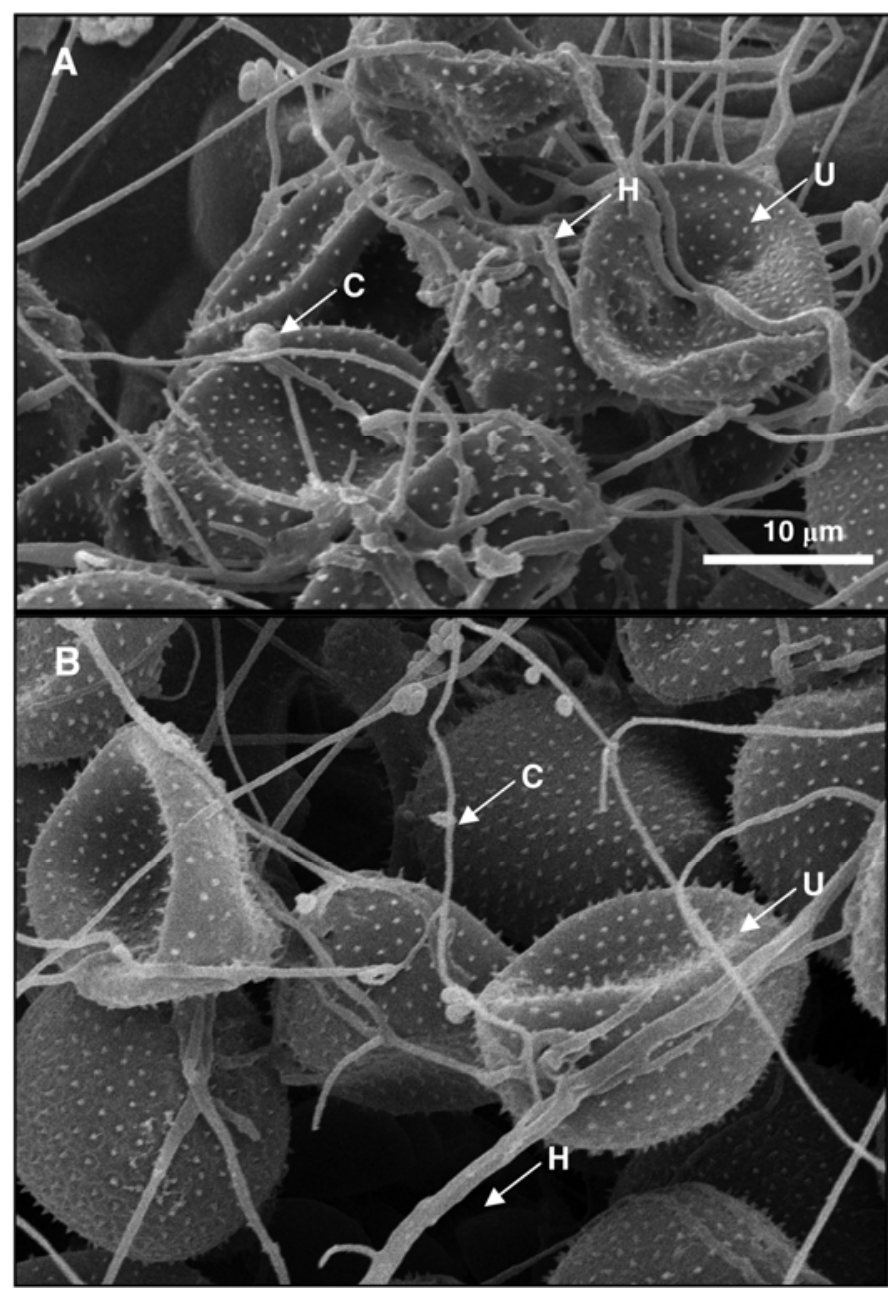

Fig. 4. Scanning electron microscope view of colonization of A, urediniospores of Phakopsora pachyrhizi by Simplicillium lanosoniveum and $\mathbf{B}$, sporulation of $S$. lanosoniveum on colonized urediniospores of $P$. pachyrhizi. Conidia $(\mathrm{C})$, hyphae $(\mathrm{H})$, and urediniospore $(\mathrm{U})$. the study. Numbers of uredinia per square centimeter did not differ significantly between inoculated treatments and the nontreated control $(P=0.51)$.

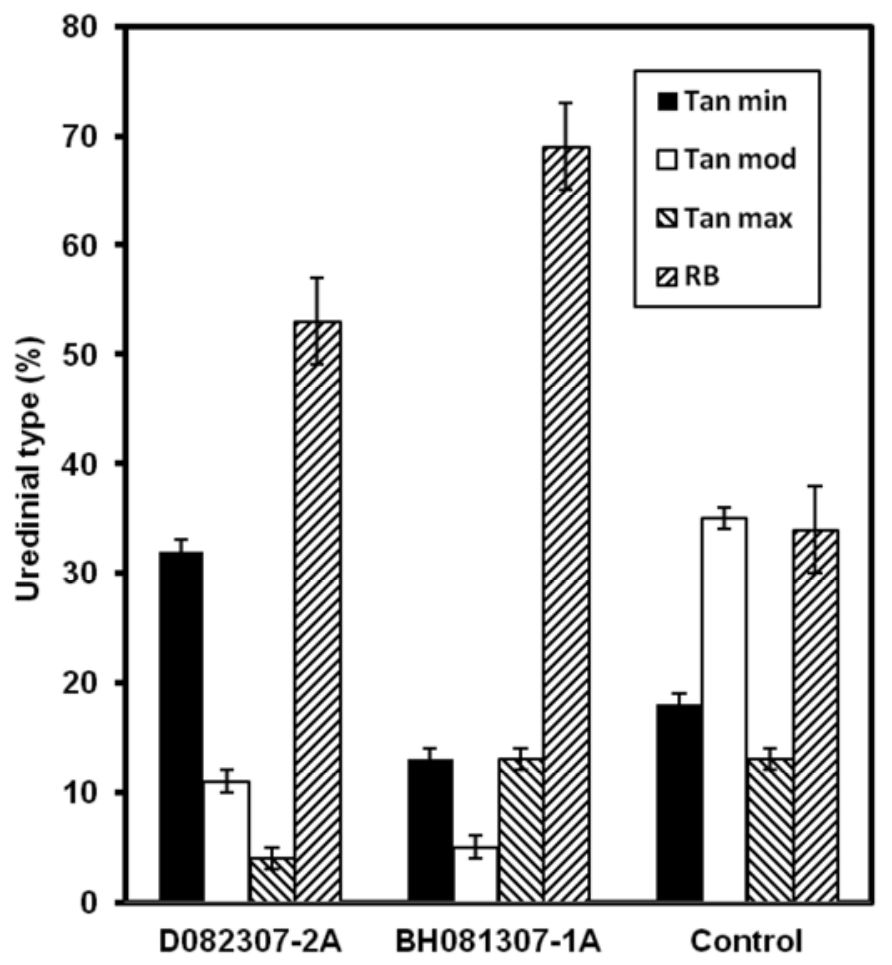

Fig. 5. Soybean rust lesion types following inoculation with conidia of Simplicillium lanosoniveum of field-grown soybean leaves showing signs and symptoms of soybean rust caused by Phakopsora pachyrhizi. Lesion types were classified at 14 days after inoculation. Red-brown uredinia were rated as RB. Sporulation in tan uredinia was rated as minimum (min), moderate (mod), or maximum (max).

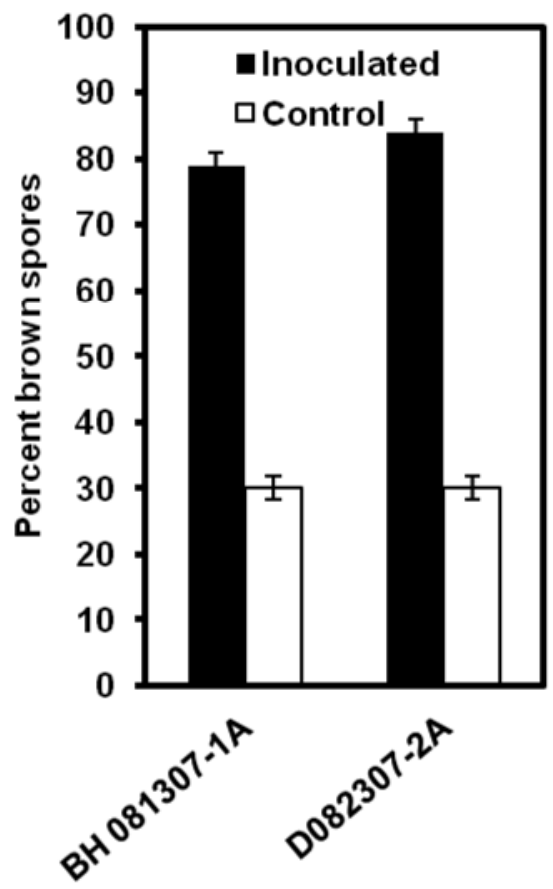

Fig. 6. Color of urediniospores of Phakopsora. pachyrhizi following inoculation of symptomatic, field-grown soybean leaves with conidia of Simplicillium lanosoniveum (BH081707-2A and D082307-2A) at 14 days after inoculation. Urediniospore color was classified as either brown or hyaline, and data are presented as percent brown spores. Bars represent standard errors of the mean. 
Field 2. Soybean rust symptoms were observed on soybeans at 68 DAP when plants reached the R5 growth stage. DNA of $P$. pachyrhizi was detected at 30 days after planting, which resulted in a latent infection period of 38 days. By physiological maturity (R7, 86 DAP), early inoculations (R1) resulted in amounts of DNA of $P$. pachyrhizi, which were not statistically different from fungicide treated leaves $(P=0.14)$. Inoculations that were made after rust symptom development resulted in amounts of rust DNA that were not significantly different from the nontreated control $(P=0.2)$ (Fig. 9A).

In order to determine initial amounts of inoculum, $S$. lanosoniveum was quantified in each treatment one hour after inoculation. In the three inoculation treatments, $0.04 \mathrm{pg}$ (s.d. = $0.01)$ and $0.06 \mathrm{pg}($ s.d. $=0.0)$ were detected in the R1 and $<2.5 \%$ rust treatments, respectively. The nontreated control contained no detectable DNA of $S$. lanosoniveum. S. lanosoniveum increased in all inoculated treatments. Most notably, when disease severity was $50 \%$ (73 DAP), the early inoculated treatment (R1) had significantly more DNA of $S$. lanosoniveum than the treatment that was inoculated at $<2.5 \%$ disease severity and the nontreated control $(P<0.01$ and 0.01 , respectively) (Fig. 9B). By the time soybean plants reached physiological maturity (86 DAP), the nontreated control and the $<2.5 \%$ treatments had significantly more uredinia per square centimeter than the R1 and fungicide treatments $(P=0.04)$, and at this time the fungicide and $\mathrm{R} 1$ treatments were equivalent (Fig. 10A and B).

Field 3. In fields that were planted before soybean rust was detected in the area, soybean rust symptoms developed at R6 (66 DAP). By the end of the study (R7), DNA of $S$. lanosoniveum decreased in early inoculations (V6 treatment). Late inoculations (R3 treatment), which were applied after detection of DNA of $P$. pachyrhizi, had significantly more DNA of $S$. lanosoniveum than the noninoculated control $(P=0.02)$ (Fig. 11A). Amounts of DNA of $P$. pachyrhizi remained low throughout this study, and there were no statistical differences in the amounts of DNA of $P$. pachyrhizi among treatments (Fig. 11B).

\section{DISCUSSION}

We previously documented that uredinia of $P$. pachyrhizi serve as a unique habitat for $S$. lanosoniveum (36). SEM micrographs

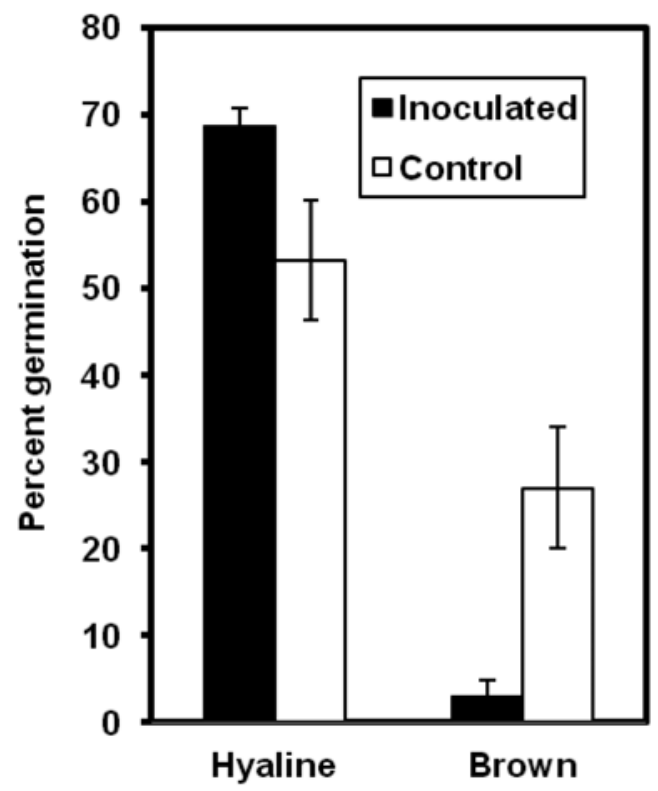

Fig. 7. Germination rates of brown and hyaline urediniospores of Phakopsora pachyrhizi, the soybean rust pathogen, following inoculation with Simplicillium lanosoniveum isolate D082307-2A. Germination rates were assessed at 14 days after inoculation. Bars represent standard errors of the mean. and attempts to recover $S$. lanosoniveum from leaves revealed that $S$. lanosoniveum was not found in association with lesions of other diseases of soybean or healthy leaf surfaces. When $S$. lanosoniveum was introduced to uredinia, structures were observed that resembled penetration sites on the surface of urediniospores. These observations suggested that $S$. lanosoniveum may be a mycoparasite of $P$. pachyrhizi, and we are addressing this possibility in further studies. Until evidence for mycoparasitism is proffered, we use the term mycophilic interaction because uredinia are the preferred niche of $S$. lanosoniveum.

In previous studies and in these experiments, $S$. lanosoniveum did not grow or establish on soybean leaf surfaces until rust uredinia erupted on co-inoculated leaves. However, in the presence of urediniospores of $P$. pachyrhizi, $S$. lanosoniveum colonized uredinia within 3 days and sporulated within 4 days. Uredinial development was repressed in both detached leaf inoculation experiments in comparison to the nontreated controls. Based on these observations and experimental results, we conclude that infection by $P$. pachyrhizi is necessary for establishment of $S$. lanosoniveum on soybean leaf surfaces.

In addition to a reduction in uredinial development, rustinfected detached soybean leaves inoculated with $S$. lanosoniveum developed 2- to 2.5-fold more red-brown lesions, which have been associated with hypersensitive resistance reactions. McLean (21) developed this color classification system in which tan lesions had two to five uredinia, and sporulation was abundant compared with red-brown lesions in which only one or two uredinia were present, and sporulation was sparse. Since then, breeders have adopted these color characteristics to differentiate between resistant and susceptible reactions $(6,15)$. We observed similar uredinial coloration, and we used a similar rating scale. However, these red-brown uredinia did not appear to be the result of a hypersensitive response because they occurred on susceptible cultivars and because tan uredinia occurred in the absence of $S$. lanosoniveum. Red-brown uredinia may be caused by necrosis

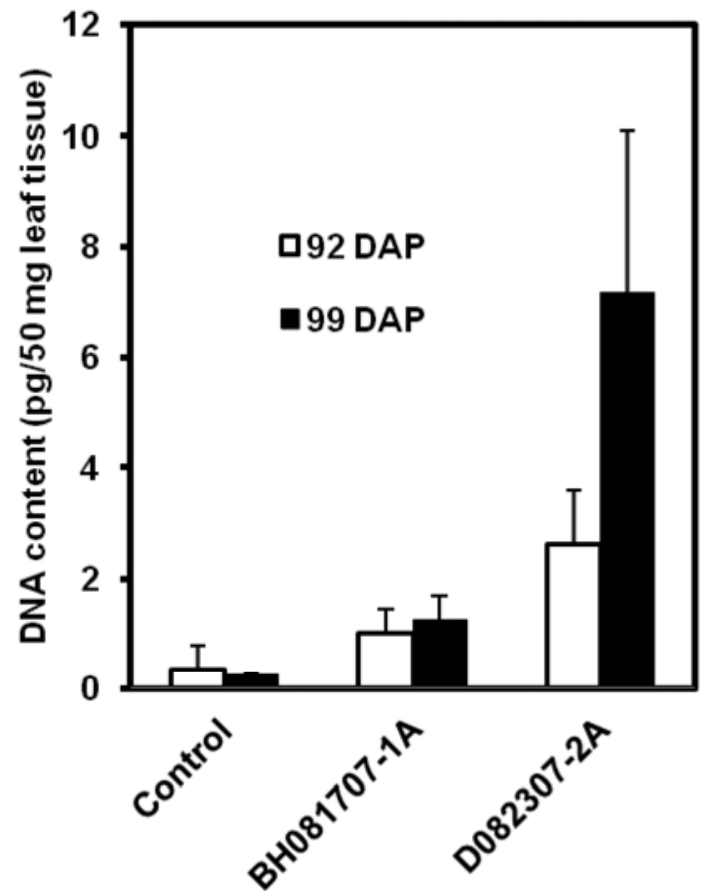

Fig. 8. Population dynamics of two isolates of Simplicillium lanosoniveum as assessed by monitoring DNA concentrations of the organisms in soybean leaves using quantitative polymerase chain reaction. Assays were conducted following inoculation of field-grown soybean plants with the antagonist $S$. lanosoniveum. Inoculum was applied 85 and 92 days after planting (DAP), and leaves were sampled 7 days after each inoculation (92 and 99 DAP). Bars represent standard errors of the mean. 
resulting from accelerated aging of uredinia that were colonized by $S$. lanosoniveum. Thus, the significant increase in red-brown uredinia in the presence of $S$. lanosoniveum mimicked an accelerated uredinial aging process that may be unrelated to hypersensitivity. Breeders and others should be aware that, in addition to a resistance reaction, there are other factors that cause red-brown uredinia.

In addition to a change in lesion color, $S$. lanosoniveum also caused a change in urediniospore color in which urediniospores became increasingly brown within 3 to 5 days after inoculation. The uredinial age study also indicated that urediniospores darkened with time, but when inoculated with S. lanosoniveum, they darkened more rapidly. Previous work indicated that uredinia of $P$. pachyrhizi sporulated for 3 weeks (20). Brown urediniospores from uredinia inoculated with the antagonist had a significantly lower germination rate. It is not clear whether this darkening of urediniospores is the result of melanization or cell decompartmentalization resulting from parasitism by the putative mycoparasite. Results from preliminary analyses indicate that the browning reaction is not caused by the accumulation of carotene or its precursors (unpublished data).

To evaluate the effects of $S$. lanosoniveum under field conditions, we conducted field trials in Louisiana and Florida in 2009 and 2010. qPCR was used to quantify the establishment of $S$. lanosoniveum and its effects on soybean rust on both diseased soybeans and disease-free plants under field conditions. In field 1, we tested two isolates of $S$. lanosoniveum. This field study utilized several commercial soybean cultivars, all with similar degrees of disease severity. Isolate D082307-2A was more effective than BH081701-1A in that it readily colonized and established in uredinia in all soybean cultivars. This difference suggests that there may be a wide range of traits among isolates
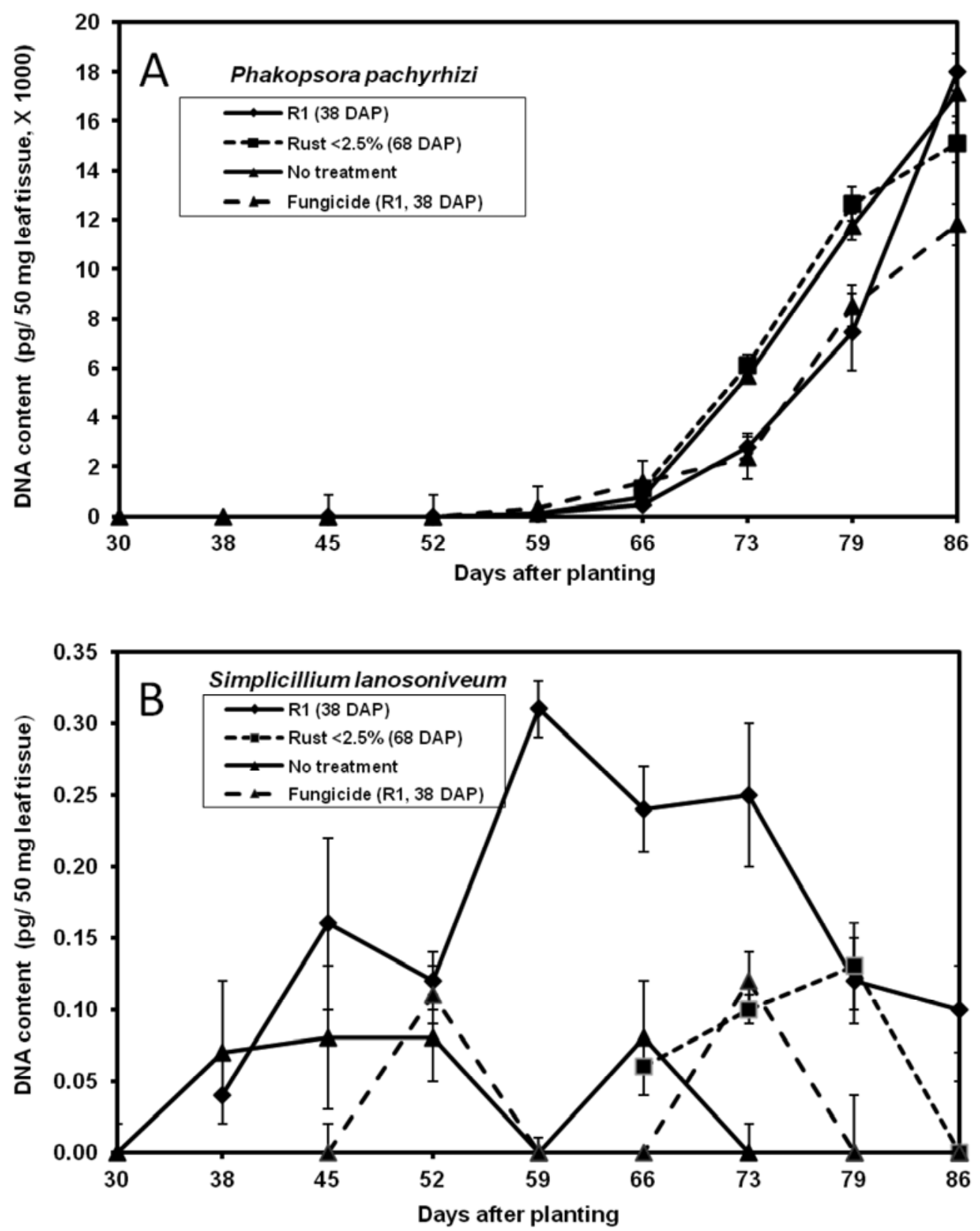

Fig. 9. Population dynamics of A, Phakopsora pachyrhizi, the soybean rust pathogen, and B, Simplicillium lanosoniveum as assessed by monitoring DNA concentrations of these organisms in soybean leaves using quantitative polymerase chain reaction. Assays were conducted on soybean leaves collected from field plots that had been subjected to the four treatments described below. Plants were inoculated with $S$. lanosoniveum either at (i) R1 when there were no symptoms of soybean rust (R1) or (ii) when rust severity was no more than $2.5 \%$ (rust $<2.5 \%$ ). Other treatments included (iii) the fungicide pyraclostrobin (fungicide) applied at R1 and (iv) a nontreated control (no treatment). Plants were sampled $1 \mathrm{~h}$ after inoculation and once per week thereafter. Bars represent standard errors of the mean. 
of $S$. lanosoniveum that affect components of the disease cycle that are necessary for epiphytotic development, e.g., rate of urediniospore production, urediniospore viability, and longevity of uredinia.

Weather probably had an effect on colonization of $S$. lanosoniveum in soybean fields. The field 1 study was conducted in October and November 2009. We suspect that there was more $S$. lanosoniveum in uredinia, as assessed with qPCR assays and observed visually, in this late-planted field than in the other studies because conditions were favorable for soybean rust development. Average high temperature was $23^{\circ} \mathrm{C}$, and rainfall totaled $9.2 \mathrm{~cm}$ during the month of the study. In field 2 in 2009 , we occasionally observed mycelia in uredinia. This field study was conducted from August through October when temperatures were lower than normal because of frequent rainstorms and cloudy skies. Maximum daytime temperatures were 30 to $33^{\circ} \mathrm{C}$, and rainfall ranged from 5.5 to $9.5 \mathrm{~cm}$ per month (weather data available from Louisiana State University Agricultural Center website www.lsuagcenter.com). The field 3 study was conducted in August and September 2010. Rainfall at this site was similar to field 2 (7 to $11 \mathrm{~cm}$ per month); however, maximum daytime
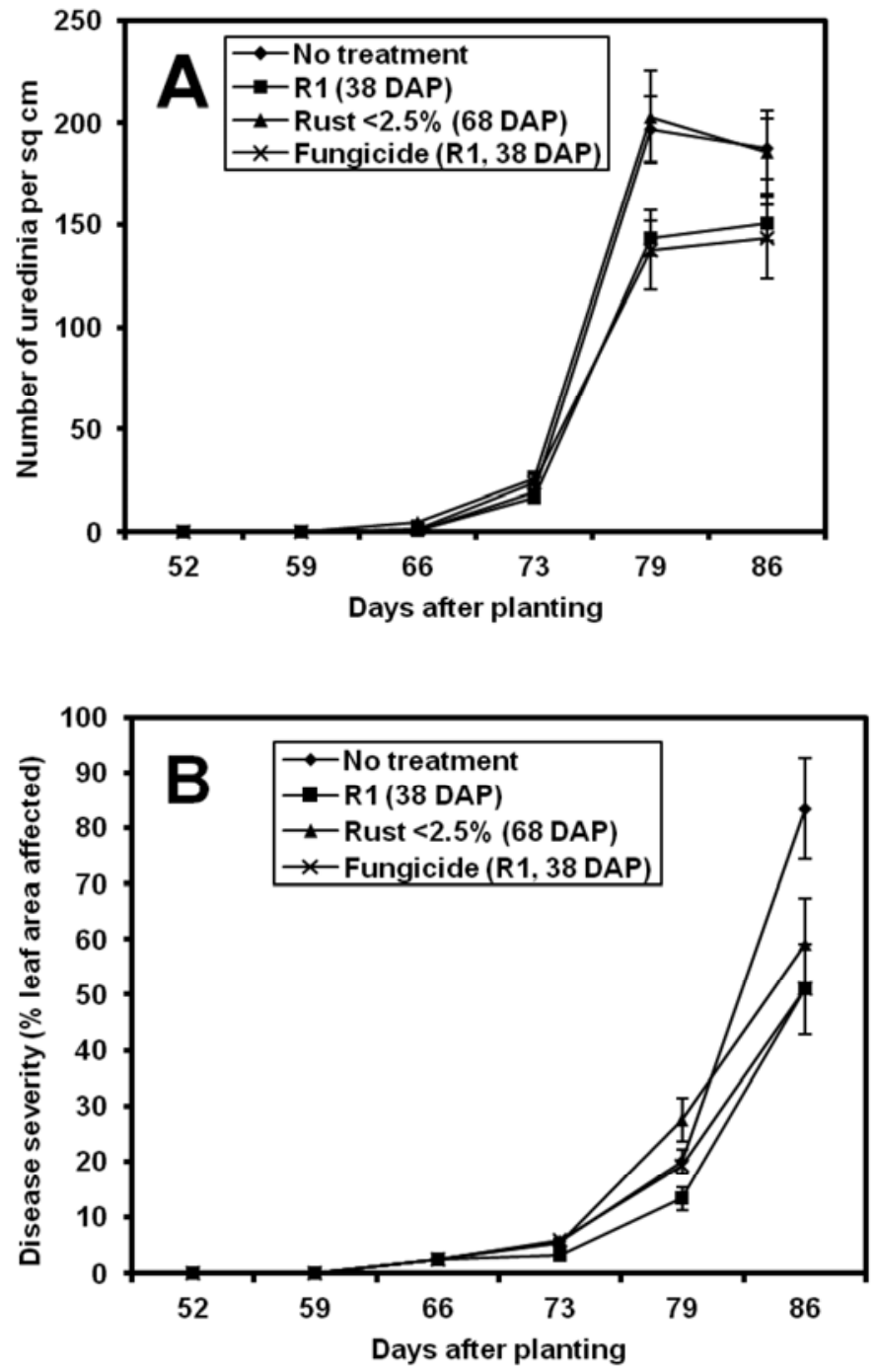

Fig. 10. A, Effects of inoculation of soybean leaves with Simplicillium lanosoniveum on soybean rust, caused by Phakopsora pachyrhizi, as assessed by numbers of uredinia per square centimeter of leaf area and $\mathbf{B}$, percent diseased leaf area as a function of days after planting. Plants were inoculated with $S$. lanosoniveum either at $\mathrm{R} 1$ when there were no symptoms of soybean rust (R1) or when rust severity was no more than $2.5 \%$ (rust $<2.5 \%$ ). Plants also were sprayed with the fungicide pyraclostrobin (fungicide) at R1, or they were not treated (no treatment). Bars represent standard errors of the mean. temperatures averaged $36^{\circ} \mathrm{C}$ (available from University of Florida website www.fawn.ifas.ulf.edu).

$S$. lanosoniveum failed to colonize field-grown leaves unless $P$. pachyrhizi was present as latent infection in the absence of uredinia or when uredinia emerged. The fungus was an aggressive colonist when uredinia were present. It is likely that spores of $P$. pachyrhizi on leaf surfaces may have provided a sufficient nutrient source to sustain $S$. lanosoniveum until uredinia developed. This phenomenon was observed in field 2 in the earliest (R1) treatment. In this instance, latent infection was detected, but disease symptoms did not occur until 30 days later. In field 3, on the other hand, $S$. lanosoniveum did not readily colonize leaves following the early (R1) inoculation. There was no latent infection at this stage, and we suspect that this was because rust inoculum was extremely low or nonexistent. The later inoculation (R3) was applied 2 weeks before symptoms developed. Latent infection was detected, and we suspect that rust inoculum was present in large enough quantities to sustain the antagonist. At this time, S. lanosoniveum began to colonize soybean leaves.
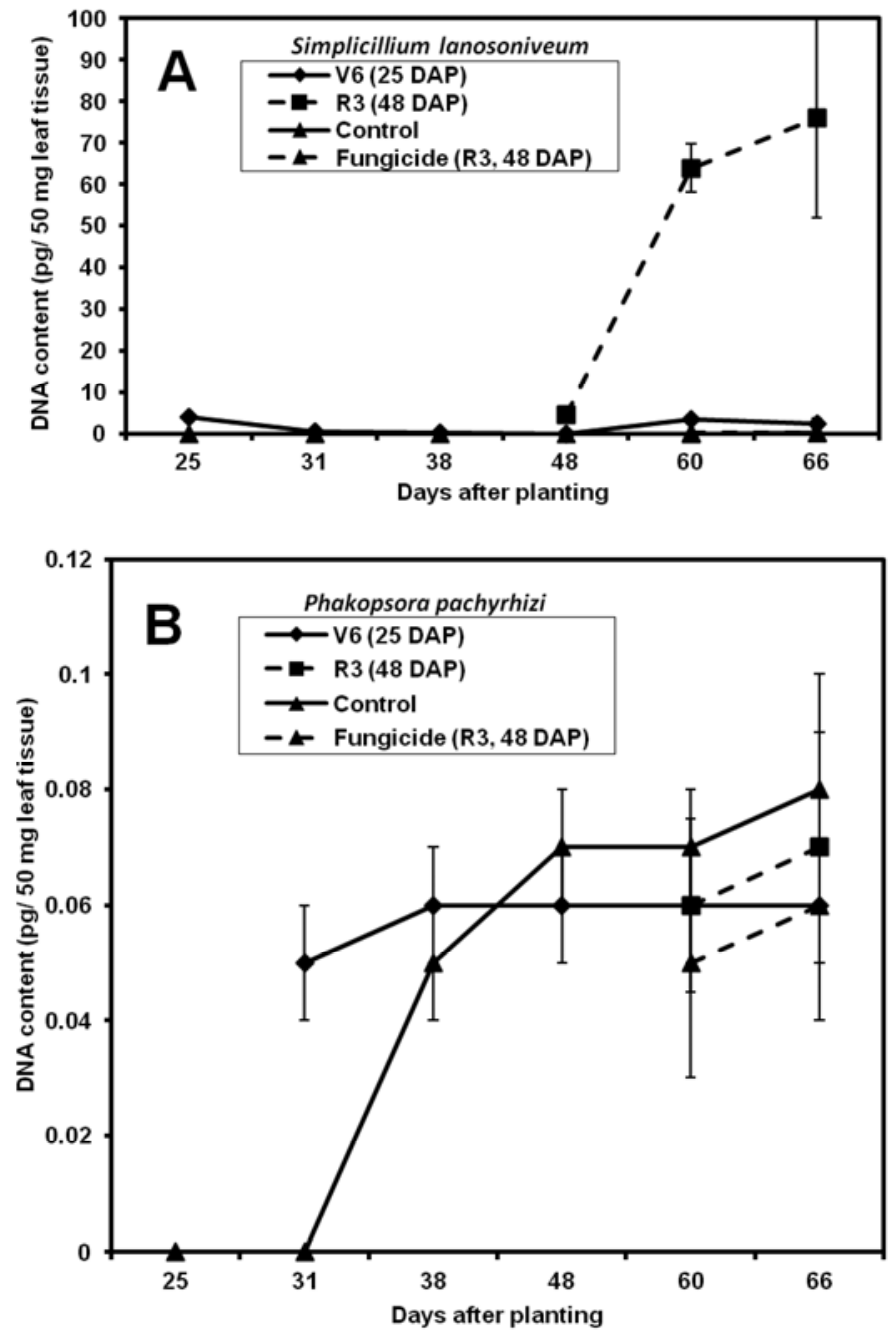

Fig. 11. Population dynamics of A, Simplicillium lanosoniveum and B, Phakopsora pachyrhizi, the soybean rust pathogen, as assessed by monitoring DNA concentrations of these organisms in soybean leaves using quantitative polymerase chain reaction. Assays were conducted following inoculation of field-grown soybean plants with the antagonist $S$. lanosoniveum. Samples were collected from field plots that had been subjected to the four treatments described below. Plants were inoculated with S. lanosoniveum at either the (i) V6 or (ii) R3 growth stages when there were no symptoms of soybean rust. Other treatments included the (iii) applications of the fungicide pyraclostrobin at R3 (fungicide) and a (iv) nontreated control (control). Sampling began $1 \mathrm{~h}$ after inoculations and continued every 7 to 10 days thereafter. Bars represent standard errors of the mean. 
In early inoculations in field 2, amounts of $S$. lanosoniveum increased significantly for the first 4 weeks after inoculation, although it fluctuated from week to week. However, at 86 DAP (R7), there were sharp decreases in amounts of $S$. lanosoniveum in the two inoculated treatments. This decrease was not associated with weather extremes such as high temperatures or dry weather. Uredinia were heavily sporulating at this point, but we observed many phylloplane inhabitants as leaves senesced. Soybean leaves became increasingly chlorotic and lesions developed necrotic margins. We suspect that competition for nutrients or exudates from uredinial inhabitants may have affected growth of $S$. lanosoniveum. This phenomenon was not observed in field 3 because soybean rust did not develop until late in the study, disease severity was extremely low, and amounts of soybean rust DNA were too small to distinguish differences.

$S$. lanosoniveum was effective in reducing the rate of disease development, and this was reflected in the DNA assays in two of the three field experiments. In the third experiment conducted in 2010, following freezing temperatures during the previous winter and the virtual elimination of kudzu foliage, which is the primary alternative host, soybean rust was not detected on soybean in Florida until July. Moreover, soybean rust was not detected within $22 \mathrm{~km}$ of this field until 11 days before symptoms were observed. Once rust inoculum was sufficient or uredinia developed, $S$. lanosoniveum readily colonized uredinia.

Questions arise about the origin of $S$. lanosoniveum. The fungus was not found in association with other soybean diseases or any of 26 other rust species in the United States (N. A. Ward, unpublished data). Accessions from the CBS culture collection were isolated from coffee rust, other fungi, and scale insects from Venezuela, Sri Lanka, Puerto Rico, and Iran (7). With the absence of $S$. lanosoniveum on other rusts and soybean diseases in south Louisiana, one possibility is that $S$. lanosoniveum was co-disseminated with urediniospores of $P$. pachyrhizi. Furthermore, while we sampled various other rusts in 2008 and 2009, the preferred habitat of S. lanosoniveum in 2007 may have been rusts that were not present in 2008 and 2009. Likewise, because Simplicillium belongs to a group of fungi that often parasitize insects, a population of insects may have been the source in 2007, and again, not present or widespread in 2008 and 2009.

Clearly, S. lanosoniveum reduced uredinial development and inhibited urediniospore germination. Its ability to inhibit urediniospore production in this polycyclic disease may confer this organism with disease-suppressing capability by reducing inoculum load, thereby limiting reinfection and delaying disease development. We conclude that $S$. lanosoniveum is an ideal candidate for biological control because it readily colonized soybean leaves and was effective in reducing disease severity. Results from these and other studies warrant the use of this antagonistic fungus as part of an IPM program in combination with other cultural practices or as a biological control agent in organic soybean production systems (36). In addition to many other pressing questions, studies should be conducted on commercial formulations with regards to shelf life and application technology.

\section{ACKNOWLEDGMENTS}

Funding for this study was provided by the Louisiana Soybean and Grain Research and Promotion Board, the USDA Southern Sustainable Agriculture Research and Education (SARE) program, and the Organic Crop Improvement Association. We thank J. Marois at the University of Florida North Florida Research and Education Center in Quincy, Florida for providing field plots. A portion of the senior author's Ph.D. dissertation was submitted to Louisiana State University and is available online at https://lsu.louislibraries.org:5203/uhtbin/cgisirsi/?ps=i77mt0VAEr/MIDLMAIN/228990013/9.

\section{LITERATURE CITED}

1. Ahrens, W. H., Cox, D. J., and Budhwar, G. 1990. Use of the arcsine and square root transformations for subjectively determined percentage data. Weed Sci. 30:452-458.

2. Arevalo, J., Hidaldo-Diaz, L., Martins, I., Souza, J., Castro, J. M. C., Carneiro, R. M., and Tigano, M. S. 2009. Cultural and morphological characterization of Pochonia chlamydosporia and Lecanicillium psalliotae isolated from Meloidogyne mayaguensis eggs in Brazil. Trop. Plant Pathol. 34:158-163.

3. Bischoff, J. F., and White, J. F. 2004. Torrubiella piperis sp. nov. (Clavicipitaceae, Hypocreales), a new teleomorph of the Lecanicillium complex. Stud. Mycol. 50:89-94.

4. Bromfield, K. R. 1964. Cold-induced dormancy and its reversal of uredospores of Puccinia graminis var. tritici. Phytopathology 54:68-74.

5. Bromfield, K. R. 1984. Soybean Rust, Monograph No. 11. American Phytopathological Society, St. Paul, MN.

6. Bromfield, K. R., Melching, J. S., and Kingsolver, C. H. 1980. Virulence and aggressiveness of Phakopsora pachyrhizi isolates causing soybean rust. Phytopathology 70:17-21.

7. Centraalbureau voor Schimmelcultures. Fungal Biodiversity Centre. http://www.cbs.knaw.nl.

8. Chen, R. S., Huang, C. C., Li, J. C., and Tsay, J. G. 2008. First Report of Simplicillium lanosoniveum causing brown spot on Salvinia auriculata and S. molesta in Taiwan. Plant Dis. 92:1589.

9. Cuthbertson, A. G. S., Blackburn, L. F., Northing, P., Luo, W. Q., Cannon, R. J. C., and Walters, K. F. A. 2008. Further compatibility tests of the entomopathogenic fungus Lecanicillium muscarium with conventional insecticide products for control of sweetpotato whitefly, Bemisia tabaci on poinsettia plants. Insect Sci. 15:355-360.

10. Dorrance, A. E., Hershman, D. E., and Draper, M. A. 2008. Economic Importance of Soybean Rust. Pages 11-19 in: Using Foliar Fungicides to Manage Soybean Rust. A. E. Dorrance, M. A. Draper, and D. E. Hershman, eds. The Ohio State University, Columbus, $\mathrm{OH}$.

11. Fehr, W. R., Caviness, C. E., Burmood, D. T., and Pennington, J. S. 1971. Stage of development descriptions for soybeans, Glycine $\max$ (L.) Merrill. Crop Sci. 11:929-931.

12. Frederick, R. D., Snyder, C. L., Peterson, G. L., and Bonde, M. R. 2002. Polymerase chain reaction assays for the detection and discrimination of the soybean rust pathogens Phakopsora pachyrhizi and P. meibomiae. Phytopathology 92:217-227.

13. Gams, W., and Zare, R. 2003. A taxonomic review of the clavicipitaceous anamorphs parasitizing nematodes and other microinvertebrates. Pages 17-73 in: Clavicipitalean Fungi: Evolutionary biology, Chemistry, Biocontrol and Cultural Impacts. J. F. White, C. W. Bacon, N. L. HywelJones, and J. W. Spatafora, eds. Marcel Dekker Inc., New York.

14. Gardes, M., and Bruns, T. D. 1993. ITS primers with enhanced specificity for basidiomycetes-application to the identification of mycorrhizae and rusts. Mol. Ecol. 2:113-118.

15. Hartman, G. L., Miles, M. R., and Frederick, R. D. 2005. Breeding for resistance to soybean rust. Plant Dis. 89:664-666.

16. Lees, A. K., Cullen, D. W., Sullivan, L., and Nicolson, M. J. 2002. Development of conventional and quantitative real-time PCR assays for the detection and identification of Rhizoctonia solani AG-3 in potato and soil. Plant Pathol. 51:293-302.

17. Levy, C. 2005. Epidemiology and chemical control of soybean rust in Southern Africa. Plant Dis. 89:669-674.

18. Levy, R., Blanche, S. B., Boquet, D. J., Golden, B., Harrell, D., Padgett, G. B., Stephenson, D., Stevens, J., Viator, S., and Udeigwe, T. K. 2011. Soybean Yields \& Production Practices 2011. Louisiana State University Agricultural Center, Baton Rouge, LA.

19. Liu, W., Xie, Y., Xue, J., Gao, Y., Zang, Y., Zhang, X., and Tan, J. 2009. Histopathological changes of Ceroplastes japonicus infected by Lecanicillium lecanii. J. Invertebr. Pathol. 101:96-105.

20. Marchetti, M. A., Uecker, F. A., and Bromfield, K. R. 1975. Uredinial development of Phakopsora pachyrhizi in soybeans. Phytopathology 65:822-823

21. McLean, R. J. 1979. Histological studies of resistance to soybean rust, Phakopsora pachyrhizi Syd. Aust. J. Agric. Res. 30:77-84.

22. Pirali-Kheirabadi, K., Haddadzadeh, H., Razzaghi-Abyaneh, M., Bokaie, S., Zare, R., Ghazavi, M., and Shams-Ghahfarokhi, M. 2007. Biological control of Rhipicephalus (Boophilus) annulatus by different strains of Metarhizium anisopliae, Beauveria bassiana, and Lecanicillium psalliotae fungi. Parasitol. Res. 100:1432-1955.

23. Polar, P., Kairo, M. T. K., Peterkin, D., Moore, D., Pegram, R., and John, S. A. 2005. Assessment of fungal isolates for development of a mycoacaricide for cattle tick control. Vector-Borne Zoo. Dis. 5:276-284.

24. Ruzin, S. E. 1999. Plant Microtechnique and Microscopy. Oxford University Press, Inc., New York.

25. Saksirirat, W., and Hoppe, H. H. 1990. Light- and scanning electron 
microscopic studies on the development of the mycoparasite Verticillium psalliotae Treschow on uredospores of the soybean rust (Phakopsora pachyrhizi Syd.). J. Phytopathol. 128:340-344.

26. Saksirirat, W., and Hoppe, H. H. 1991. Degradation of uredospores of the soybean rust fungus (Phakopsora pachyrhizi Syd.) by cell-free culture filtrates of the mycoparasite Verticilium psalliotae Treschow. J. Phytopathol. 132:33-45.

27. Saksirirat, W., and Hoppe, H. H. 1991. Secretion of extracellular enzymes by Verticllium psalliotae Treschow and Verticllium lecanii (Zimm.) Viegas during growth on uredospores of the soybean rust fungus (Phakopsora pachyrhizi Syd.) in liquid cultures. J. Phytopathol. 131:161-173.

28. Sass, J. E. 1958. Botanical Microtechnique. The Iowa State University Press, Ames, IA.

29. Schneider, R. W., Hollier, C. A., Whitam, H. K., Palm, M. E., McKemy, J. M., Hernãndez, J. R., Levy, L., and DeVries-Paterson, R. 2005. First report of soybean rust caused by Phakopsora pachyrhizi in the continental United States. Plant Dis. 89:774.

30. Schneider, R. W., Sikora, E., Padgett, B., and Sciumbato, G. 2008. Managing Late-Season Soybean Diseases and Soybean Rust: A Southern Perspective. Pages 72-75 in: Using Foliar Fungicides to Manage Soybean Rust. A. E. Dorrance, M. A. Draper, and D. E. Hershman, eds. The Ohio State University, Columbus, $\mathrm{OH}$.

31. Spencer, D. M. 1980. Parasitism of carnation rust (Uromyces dianthi) by Verticillium lecanii. Trans. Br. Mycol. Soc. 74:191-194.
32. Sung, G., Hywel-Jones, N., Sung, J., Luangsa-ard, J. J., Shrestha, B., and Spatafora, J. W. 2007. Phylogenetic classification of Cordyceps and the clavicipitaceous fungi. St. Mycol. 57:5-59.

33. Tukey, J. W. 1977. Exploratory Data Analysis. Addison-Wesley, MA.

34. U.S. Department of Agriculture. Soybean Rust IPM PIPE. Southern Region Integrated Pest Management. http://sbr.ipmpipe.org.

35. Walker, D. R., Boerma, H. R., Phillips, D. V., Schneider, R. W., Buckley, J. B., Shipe, E. R., Mueller, J. D., Weaver, D. B., Sikora, E. J., Moore, S. H., Hartman, G. L., Miles, M. R., Harris, D. K., Wright, D. L., Marois, J. J., and Nelson, R. L. 2011. Evaluation of USDA soybean germplasm accessions for resistance to soybean rust in the southern United States. Crop Sci. 51:678-693.

36. Ward, N. A., Schneider, R. W., and Aime, M. C. 2011. Colonization of soybean rust sori by Simplicillium lanosoniveum. Fungal Ecol. 4:303-308.

37. Yang, X. B., Tschanz, A. T., Dowler, W. M., and Wang, T. C. 1991 Development of yield loss models in relation to reductions of components of soybean infected with Phakopsora pachyrhizi. Phytopathology 81:1420-1426.

38. Yuan, Z. W., Pei, M. H., Hunter, T., Ruiz, C., and Royle, D. J. 1999. Pathogenicity to willow rust, Melampsora epitea, of the mycoparasite Sphaerellopsis filum from different sources. Mycol. Res. 103:509-512.

39. Zare, R., and Gams, W. 2001. A revision of Verticillium section Prostrata IV. The genera Lecanicillium and Simplicillium gen. nov. Nova Hedwigia $73: 1-50$.

\section{Erratum}

The reverse primer SimpR-NW and probe SimpPR-NW sequences have been corrected on page 752 . Changes to this article were made on August 1, 2014. 